\title{
Triglycerides Mediate Body Mass Index and Nonalcoholic Fatty Liver Disease: A Population-Based Study
}

\author{
Jie Xing ${ }^{\mathrm{a}}$ Xue Guan ${ }^{\mathrm{a}}$ Qian Zhang ${ }^{\mathrm{a}}$ Shuohua Chen ${ }^{\mathrm{b}}$ Shouling Wu ${ }^{\mathrm{b}}$ \\ Xiujing Sun ${ }^{a}$ \\ a Department of Gastroenterology, Beijing Friendship Hospital, Capital Medical University, Beijing, China; \\ ${ }^{\mathrm{b}}$ Department of Cardiology, Kailuan General Hospital, Tangshan, China
}

\section{Keywords}

Nonalcoholic fatty liver disease - Body mass index .

Triglycerides - Obesity

\begin{abstract}
Introduction: Nonalcoholic fatty liver disease (NAFLD) is defined by the accumulation of triglycerides (TG). The body mass index (BMI) is associated with NAFLD. This large-scale cohort study was performed to evaluate and quantify the mediating effect of TG on the association between BMI and NAFLD. Methods: In total, 15,943 participants in the Kailuan Group were recruited between 2010 and 2014. The impact of TG on the association between BMI and NAFLD was determined through a mediation analysis. Results: BMI was an independent risk factor for incident NAFLD, with OR of 1.416 (95\% Cl 1.338-1.499) and 1.187 (95\% Cl 1.137-1.240) in the low-BMI and high-BMI groups, respectively $(p<0.001)$. The TG level was a risk factor for NAFLD in the high-BMI group, with an OR of 2.775 ( $95 \% \mathrm{Cl} 1.488-5.177 ; p=0.001)$. Positive associations between BMI and the TG level remained in the 2 above mentioned groups after adjusting for confounders $(\beta=0.072$ and $0.032 ; p<0.001)$. The mediation analysis revealed that TG contributed to $26.050 \%$ of incident NAFLD in the high-BMI group $(p=0.01)$. Conclusion: A high BMI was
\end{abstract}

karger@karger.com www.karger.com/ofa

Karger"

BOPEN ACCESS
(C) 2021 The Author(s)

Published by S. Karger AG, Basel

This is an Open Access article licensed under the Creative Commons Attribution-NonCommercial-4.0 International License (CC BY-NC) (http://www.karger.com/Services/OpenAccessLicense), applicable to the online version of the article only. Usage and distribution for commercial purposes requires written permission. an independent risk factor for incident NAFLD, and a high TG level was a risk factor in the high-BMI group (BMI $\geq 24$ ). TG contributes about $25 \%$ to incident NAFLD in people with obesity.

(C) 2021 The Author(s)

Published by S. Karger AG, Basel

\section{Introduction}

Nonalcoholic fatty liver disease (NAFLD) is a clinicopathological manifestation characterized by significant hepatic steatosis without an excessive alcohol intake $(>20$ $\mathrm{g}$ /day for women and $>30 \mathrm{~g} /$ day for men) [1], ranging from simply fatty liver to more aggressive nonalcoholic steatohepatitis and even liver cirrhosis, hepatocellular carcinoma (HCC), and end-stage liver failure. NAFLD is the second most common cause of liver transplantation in the USA [2]. NAFLD has rapidly become a public health problem in China in the last decade [3]. Approximately $20-33 \%$ of adults are troubled by NAFLD according to a previous study [4]. Insulin resistance (IR) plays a

\section{J.X. and X.G. contributed equally to this work.}


key role in the pathogenesis of NAFLD [5], and resistance to the action of insulin changes the lipid metabolism by enhancing peripheral lipolysis, increasing triglyceride (TG) synthesis, and increasing the hepatic uptake of fatty acids; each of these factors may contribute to the accumulation of hepatocellular TG [6], which has been generally acknowledged as the hallmark feature of NAFLD [7] both histologically and metabolically. The accumulation of TG has been partly attributed to obesity [8]. Therefore, the relationships between body mass index (BMI), TG, and NAFLD appear to be complicated, and it is important to identify which of the above 3 factors mediate the associations.

This large cohort study aimed to investigate the associations of NAFLD with BMI and TG and to determine whether the effect of BMI on NAFLD is mediated by TG.

\section{Materials and Methods}

\section{Screening Populations}

We used data from a subset of the Kailuan Group, an ongoing prospective multicenter cohort study based on the Kailuan community in Tangshan City in northern China (trial registration No. ChiCTR-TNRC-11001489) [9]. The employees of the Tangshan Kailuan Company underwent questionnaire and clinical and laboratory examinations every 2 years; these were conducted in the 11 hospitals responsible for the healthcare of the community, with the same strategy to update the information. This study enrolled only participants who fulfilled the following inclusion criteria: (1) employees (including the retired) who participated in physical examinations regularly and (2) patients aged $\geq 18$ years.

\section{Study Cohort}

The population screened in 2010 was used as the baseline population in this study, with a total of 92,967 participants from the cohort enrolled. Two follow-up physical examinations were conducted in 2012 and 2014 in the same hospital. Participants were excluded if they had any of the following: (1) new findings of fatty liver disease (FLD) at baseline, (2) a history of alcohol intake or long-term medication use, (3) a history of chronic hepatitis $\mathrm{C}$ or HBsAg positivity, and (4) any missing data on baseline information, laboratory examination, or abdominal ultrasound. Ultimately, 15,943 participants were included in the current analyses.

NAFLD was defined in the cohort as follows: (1) a lack of evidence such as significant alcohol consumption and long-term use of medication and (2) ultrasound findings of FLD. Abdominal ultrasonography was performed and assessed by experienced clinicians who were blinded to the clinical presentation and laboratory findings. According to a previous study, fatty liver was diagnosed and divided into mild, moderate, and severe categories according to ultrasonographic liver features based on established criteria [10]. Alcohol intake was defined as any form of alcohol intake (e.g., beer, white spirits with a high or low content of aromatics, and wine).

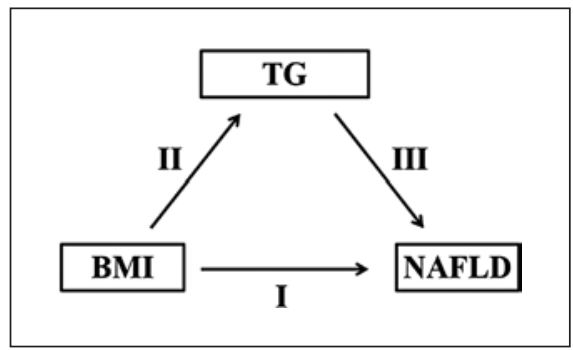

Fig. 1. TG mediated the association between BMI and NAFLD in 15,943 individuals in the Kailuan Group. Path I represents the direct and total effects; paths II and III together represent the indirect effect.

\section{Assessment of Baseline Characteristics}

The baseline data were obtained from a self-reported questionnaire that included demographic variables (such as age and sex), occupation, alcohol use, level of physical activity, education level, the income of each respondent per month, smoking status, and medical history (e.g., antihypertensive medications) in person by research doctors in 2010.

Body height and weight were assessed while the participants were wearing light clothing without shoes or a hat by trained field workers during the surveys. Height was measured to the nearest $0.1 \mathrm{~cm}$ using a portable stadiometer, and weight was measured to the nearest $0.1 \mathrm{~kg}$ using calibrated platform scales. BMI was calculated as body weight $(\mathrm{kg})$ divided by height $(\mathrm{m})$ squared [12] and used to define overweight or obesity. Participants were grouped according to BMI into a low-BMI group (BMI <24) and a highBMI group (BMI $\geq 24)$ [13].

Blood pressure (BP) was measured at the left arm in a seated position to the nearest $1 \mathrm{~mm} \mathrm{Hg}$ using a mercury sphygmomanometer following standard recommended procedures. Three readings of systolic $\mathrm{BP}(\mathrm{SBP})$ and diastolic $\mathrm{BP}$ (DBP) were recorded in 5-min intervals after the participants had rested in a chair for at least $5 \mathrm{~min}$. The average of the 3 readings was used for data analysis. If 2 of the 3 measurements differed by more than $5 \mathrm{~mm}$ $\mathrm{Hg}$, then an additional reading was taken.

Overnight fasting blood samples were assessed from the antecubital vein in the morning and transfused into vacuum tubes containing EDTA for storage. Plasma was separated and stored at $-80^{\circ} \mathrm{C}$ for subsequent analyses. Fasting blood glucose (FBG) was measured using the hexokinase/glucose-6-phosphate dehydrogenase method. Total cholesterol (TC) and TG was measured using enzymatic methods. All biochemical variables were measured on an autoanalyzer at the central laboratory of the Kailuan General Hospital $[14,15]$.

\section{Statistical Analysis}

Normally distributed continuous data such as BMI and TG are presented as means \pm SD and were analyzed with a Student $t$ test. Categorical variables such as sex are presented as percentages and were compared using a $\chi^{2}$ test, and the Wilcoxon rank-sum test was used to test for differences in continuous variables between study subjects and reference intervals. A multivariate logistic regression analysis was used to reveal the associations of NAFLD with BMI and TG and to minimize study heterogeneity. The pa- 


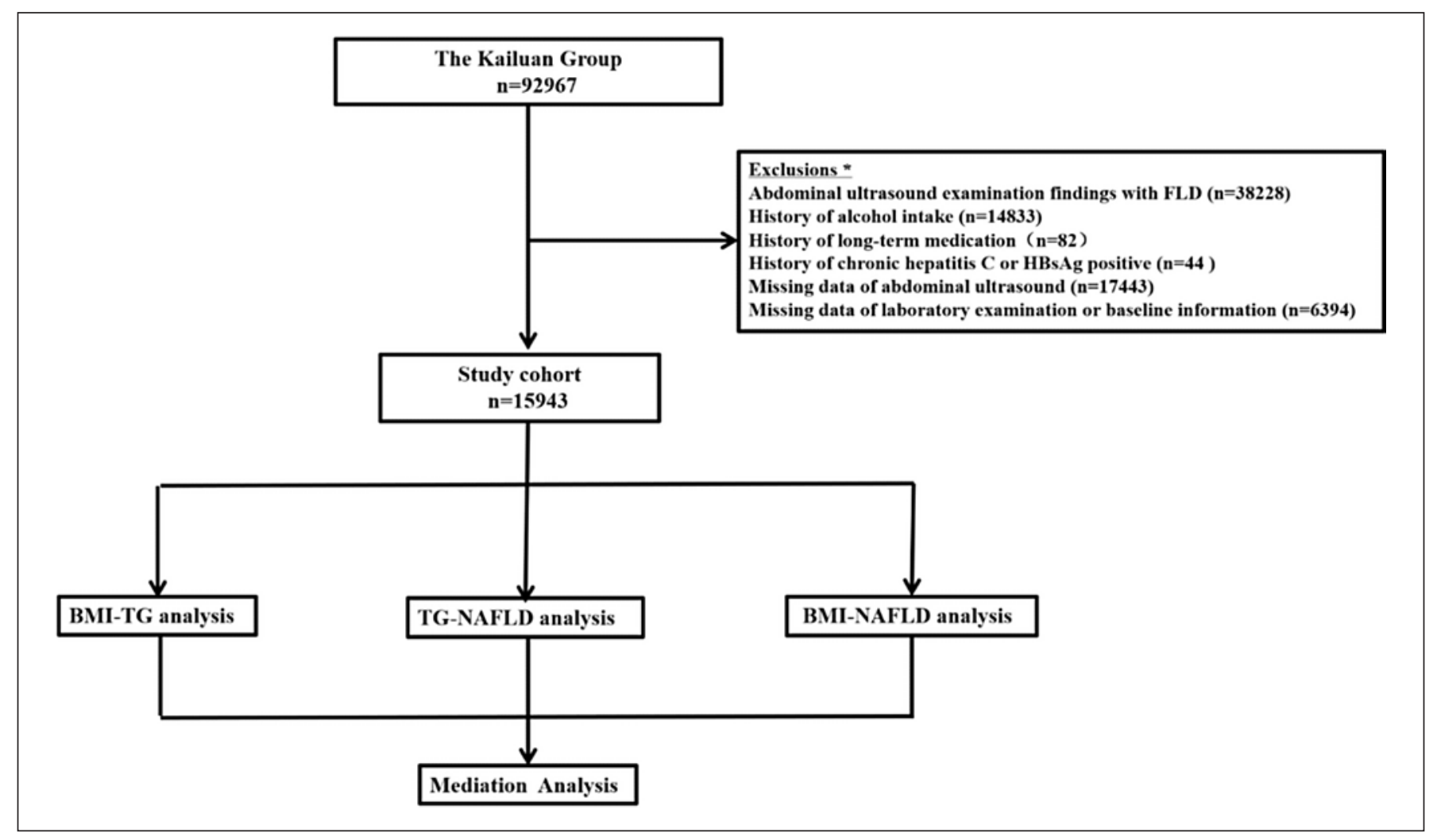

Fig. 2. Study design and inclusion and exclusion criteria. ${ }^{*}$ Participants could fulfill more than 1 exclusion criterion.

tients were divided into several groups according to BMI. The covariates that might have an impact on NAFLD (age, sex, smoking status, marital status, work type, education level, physical exercise, income, BMI, SBP, FBG, uric acid [UA], C-reactive protein [CRP], creatinine $[\mathrm{Cr}], \mathrm{LDL}$, and $\mathrm{HDL}$ ) were included in this analysis. The OR and 95\% CI were estimated. A multivariate linear regression model was also used to reveal the associations of BMI and TG. The general group was divided into subgroups according to BMI. The covariates that might have an impact (smoking status, marital status, work type, education level, physical exercise, and income) were adjusted for in this analysis. The $\beta$ value and 95\% CI were estimated.

A mediation analysis was conducted to determine whether the effect of the treatment variable (BMI) on the outcome variable (NAFLD) was mediated by the mediator variable (TG). Figure 1 shows the conceptual version of the model used in our mediation analysis. The mediation analysis could quantify the total effect (the association between BMI and NAFLD), the natural direct effect (the effect with the influence of TG), and the natural indirect effect (the effect of BMI on NAFLD attributable to TG). To measure the adjusted mediation effect, the covariates age, gender, SBP, smoking status, marital status, work type, education, physical exercise, income, TC, FBG, UA, CRP, and Cr were adjusted for in the mediation analysis. $p<0.05$ was considered statistically significant. All statistical analyses were performed with SAS 9.3 (SAS Institute Inc., Cary, NC, USA).

\section{Results}

\section{Overall Characteristics of the Cohort}

The 2010 Kailuan Group included 92,967 participants; 77,024 were excluded and 15,943 participants were included in the current study, as shown in Figure 2.

The overall characteristics of the study population are shown in Table 1. In total, 8,644 (54.22\%) subjects were classified as the low-BMI group, and 7,299 (45.78\%) were classified as the high-BMI group. Age, BMI, SBP, DBP, TG, TC, FBG, UA, CRP, and Cr data are presented as means $\pm \mathrm{SD}$, while gender, smoking status, marital status, work type, education level, physical exercise, income, and NAFLD status data are presented as percentages. Compared with the low-BMI group, the aged male participants in the high-BMI group had significantly higher levels of SBP, DBP, TG, TC, UA, Cr, CRP, and FBG. Smoking status was not significantly different between the 2 BMI groups. 
Table 1. Comparison of characteristics of the participants with the BMI level at baseline

\begin{tabular}{|c|c|c|c|c|}
\hline Characteristic & $\begin{array}{l}\text { Total } \\
(n=15,943)\end{array}$ & $\begin{array}{l}\text { Low BMI }(<24 \\
n=8,644)\end{array}$ & $\begin{array}{l}\text { High BMI }(\geq 24 \\
n=7,299)\end{array}$ & $p$ value \\
\hline Age, years & $50.89 \pm 13.08$ & $49.64 \pm 13.62$ & $52.38 \pm 12.24$ & $<0.001$ \\
\hline \multicolumn{5}{|l|}{ Gender } \\
\hline Female & $5,189(32.55)$ & $3,106(35.93)$ & $2,083(28.54)$ & \multirow[t]{2}{*}{$<0.001$} \\
\hline Male & $10,754(67.45)$ & $5,538(64.07)$ & $5,216(71.46)$ & \\
\hline \multicolumn{5}{|l|}{ Smoker status } \\
\hline Never or ex & $11,604(72.78)$ & $6,290(72.77)$ & $5,314(72.80)$ & \multirow[t]{2}{*}{0.586} \\
\hline Current & $4,339(27.22)$ & $2,354(27.23)$ & $1,985(27.20)$ & \\
\hline \multicolumn{5}{|l|}{ Marital status } \\
\hline Married & $15,357(96.32)$ & $8,241(95.34)$ & $7,116(97.49)$ & \multirow[t]{2}{*}{$<0.001$} \\
\hline Other & $586(3.68)$ & $403(4.66)$ & $183(2.51)$ & \\
\hline \multicolumn{5}{|l|}{ Work type } \\
\hline Mental & $2,607(16.35)$ & $1,609(18.61)$ & $998(13.67)$ & \multirow[t]{2}{*}{$<0.001$} \\
\hline Physical & $13,336(83.65)$ & $7,035(81.39)$ & $6,301(86.33)$ & \\
\hline \multicolumn{5}{|l|}{ Education level } \\
\hline Below high school & $10,978(68.85)$ & $5,585(64.61)$ & $5,393(73.89)$ & \multirow[t]{2}{*}{$<0.001$} \\
\hline High school and above & $4,965(31.15)$ & $3,059(35.39)$ & $1,906(26.11)$ & \\
\hline \multicolumn{5}{|c|}{ Physical exercise } \\
\hline No & $4,836(30.33)$ & $2,698(31.21)$ & $2,138(29.29)$ & \multirow[t]{2}{*}{0.009} \\
\hline Yes & $11,107(69.67)$ & $5,946(68.79)$ & $5,161(70.71)$ & \\
\hline \multicolumn{5}{|l|}{ Income } \\
\hline$<$ JPY $1,000 /$ month & $7,243(45.43)$ & $4,036(46.69)$ & $3,207(43.94)$ & \multirow{2}{*}{0.001} \\
\hline$\geq$ JPY $1,000 /$ month & $8,700(54.57)$ & $4,608(53.31)$ & $4,092(56.06)$ & \\
\hline $\mathrm{SBP}, \mathrm{mm} \mathrm{Hg}$ & $126.14 \pm 18.96$ & $122.41 \pm 18.38$ & $130.54 \pm 18.69$ & $<0.001$ \\
\hline $\mathrm{DBP}, \mathrm{mm} \mathrm{Hg}$ & $81.65 \pm 10.37$ & $79.53 \pm 9.97$ & $84.16 \pm 10.27$ & $<0.001$ \\
\hline $\mathrm{TG}, \mathrm{mmol} / \mathrm{L}$ & $1.10(0.81-1.50)$ & $1.02(0.74-1.38)$ & $1.22(0.91-1.69)$ & $<0.001$ \\
\hline $\mathrm{TC}, \mathrm{mmol} / \mathrm{L}$ & $4.73(4.17-5.30)$ & $4.68(4.11-5.21)$ & $4.80(4.22-5.37)$ & $<0.001$ \\
\hline $\mathrm{FBG}, \mathrm{mmol} / \mathrm{L}$ & $5.17(4.80-5.62)$ & $5.10(4.72-5.53)$ & $5.23(4.88-5.70)$ & $<0.001$ \\
\hline $\mathrm{UA}, \mu \mathrm{mol} / \mathrm{L}$ & $263.00(215.00-318.00)$ & $255.00(211.00-309.00)$ & $273.00(219.00-328.20)$ & $<0.001$ \\
\hline $\mathrm{CRP}, \mathrm{mg} / \mathrm{L}$ & $0.90(0.40-2.03)$ & $0.78(0.30-1.70)$ & $1.07(0.50-2.40)$ & $<0.001$ \\
\hline $\mathrm{Cr}, \mu \mathrm{mol} / \mathrm{L}$ & $78.90(66.40-94.70)$ & $77.00(64.60-93.40)$ & $80.00(68.90-95.90)$ & $<0.001$ \\
\hline
\end{tabular}

Values are presented as means \pm SD or numbers (\%).

\section{Relationship between BMI/TG and NAFLD}

The results are shown in Table 2. The OR (95\% CI) of the relationship between BMI and NAFLD in the lowBMI group and the high-BMI group was 1.416 (1.338$1.499)$ and $1.187(1.137-1.240)$, respectively $(p<0.001)$, suggesting that BMI is a significant risk factor for NAFLD.

The analysis revealed that TG, as a risk factor, was associated with NAFLD in the high-BMI group, with an OR (95\% CI) of 2.775 (1.488-5.177; $p=0.001)$. Similar results were not observed in the low-BMI group $(p=0.115)$.

\section{Relationship between BMI and TG}

The results are shown in Table 3. The analysis revealed that BMI was also significantly associated with TG in the low-BMI $(\beta=0.072,0.047$, and 0.097) and high-BMI $(\beta=0.032,0.017$, and 0.047$)$ groups $(p<0.001)$.

\section{Mediation Analysis}

Table 2 shows that BMI was an independent risk factor for the development of NAFLD, while TG was a risk factor for NAFLD in the high-BMI group only. Thus, we analyzed the effect of TG in mediating the association between BMI and the development of NAFLD. The results are shown in Table 4 . There was no significant association in the low-BMI group $(p>0.05)$; however, regarding the subgroup with a BMI $\geq 24$, the mediation analysis showed that the total effect on the OR scale was 1.135 (95\% CI $1.030-1.250$ ), with a natural direct effect and a natural indirect effect of 1.100 (95\% CI $0.993-1.219)$ and 1.032 (95\% CI 1.007-1.057), respectively ( $p=0.01)$. Therefore, approximately $26.050 \%$ of the BMI effect on NAFLD was mediated through TG levels in the high-BMI group. No mediation effect was observed in the low-BMI group. 
Table 2. Factors that influenced NAFLD in the low-BMI and highBMI groups

\begin{tabular}{llllr}
\hline & OR & $\begin{array}{l}95 \% \mathrm{CI} \\
\text { (lower } \\
\text { limit) }\end{array}$ & $\begin{array}{l}\text { 95\% CI } \\
\text { lupper } \\
\text { limit) }\end{array}$ & $p$ value \\
& & & & \\
\hline Low-BMI group & & & \\
Age (years) & 0.996 & 0.991 & 1.002 & 0.190 \\
Gender & 0.898 & 0.776 & 1.037 & 0.144 \\
BMI $\left(\mathrm{kg} / \mathrm{m}^{2}\right)$ & 1.416 & 1.338 & 1.499 & $<0.001$ \\
SBP $(\mathrm{mm} \mathrm{Hg})$ & 1.003 & 0.999 & 1.006 & 0.127 \\
TG $(\mathrm{mmol} / \mathrm{L})$ & 1.785 & 0.868 & 3.669 & 0.115 \\
TC $(\mathrm{mmol} / \mathrm{L})$ & 1.095 & 1.042 & 1.150 & $<0.001$ \\
FBG $(\mathrm{mmol} / \mathrm{L})$ & 1.002 & 0.973 & 1.033 & 0.880 \\
UA $(\mu \mathrm{mol} / \mathrm{L})$ & 1.002 & 1.001 & 1.002 & $<0.001$ \\
CRP $(\mathrm{mg} / \mathrm{L})$ & 1.011 & 1.001 & 1.022 & 0.039 \\
Cr $(\mu \mathrm{mol} / \mathrm{L})$ & 1.001 & 0.999 & 1.003 & 0.485 \\
High-BMI group & & & & \\
Age $(\mathrm{years})$ & 0.990 & 0.985 & 0.995 & $<0.001$ \\
Gender & 0.806 & 0.710 & 0.914 & 0.001 \\
BMI $\left(\mathrm{kg} / \mathrm{m}^{2}\right)$ & 1.187 & 1.137 & 1.240 & $<0.001$ \\
SBP $(\mathrm{mm} \mathrm{Hg})$ & 1.002 & 1.000 & 1.005 & 0.092 \\
TG $(\mathrm{mmol} / \mathrm{L})$ & 2.775 & 1.488 & 5.177 & 0.001 \\
TC $(\mathrm{mmol} / \mathrm{L})$ & 1.033 & 0.991 & 1.077 & 0.123 \\
FBG $(\mathrm{mmol} / \mathrm{L})$ & 1.062 & 1.023 & 1.104 & 0.002 \\
UA $(\mu \mathrm{mol} / \mathrm{L})$ & 1.001 & 1.000 & 1.001 & 0.006 \\
CRP $(\mathrm{mg} / \mathrm{L})$ & 1.016 & 1.005 & 1.027 & 0.003 \\
Cr $(\mu \mathrm{mol} / \mathrm{L})$ & 1.001 & 0.999 & 1.003 & 0.467 \\
\hline
\end{tabular}

Adjusted for marital status, smoking status, work type, education level, physical exercise, and income. ${ }^{\text {a }} \mathrm{BMI}<24$. ${ }^{\mathrm{b}} \mathrm{BMI} \geq 24$.
Table 3. Association between BMI and TG in the Kailuan Group

\begin{tabular}{|c|c|c|c|c|}
\hline & $\beta$ & $\begin{array}{l}95 \% \text { CI } \\
\text { (lower } \\
\text { limit) }\end{array}$ & $\begin{array}{l}95 \% \text { CI } \\
\text { (upper } \\
\text { limit) }\end{array}$ & $p$ value \\
\hline \multicolumn{5}{|l|}{ Low-BMI group ${ }^{a}$} \\
\hline Age (years) & -0.004 & -0.008 & -0.001 & 0.026 \\
\hline Gender & 0.024 & -0.080 & 0.128 & 0.652 \\
\hline BMI $\left(\mathrm{kg} / \mathrm{m}^{2}\right)$ & 0.072 & 0.047 & 0.097 & $<0.001$ \\
\hline $\mathrm{SBP}(\mathrm{mm} \mathrm{Hg})$ & 0.002 & -0.000 & 0.004 & 0.115 \\
\hline $\mathrm{TC}(\mathrm{mmol} / \mathrm{L})$ & 0.116 & 0.079 & 0.152 & $<0.001$ \\
\hline $\mathrm{FBG}(\mathrm{mmol} / \mathrm{L})$ & 0.031 & 0.008 & 0.152 & 0.009 \\
\hline $\mathrm{UA}(\mu \mathrm{mol} / \mathrm{L})$ & 0.001 & 0.000 & 0.001 & 0.045 \\
\hline $\mathrm{CRP}(\mathrm{mg} / \mathrm{L})$ & 0.002 & -0.006 & 0.011 & 0.612 \\
\hline $\mathrm{Cr}(\mu \mathrm{mol} / \mathrm{L})$ & 0.001 & -0.001 & 0.003 & 0.281 \\
\hline \multicolumn{5}{|l|}{ High-BMI group ${ }^{b}$} \\
\hline Age (years) & -0.013 & -0.017 & -0.010 & $<0.001$ \\
\hline Gender & -0.024 & -0.105 & 0.057 & 0.564 \\
\hline BMI $\left(\mathrm{kg} / \mathrm{m}^{2}\right)$ & 0.032 & 0.017 & 0.047 & $<0.001$ \\
\hline $\mathrm{SBP}(\mathrm{mm} \mathrm{Hg})$ & 0.001 & -0.000 & 0.003 & 0.107 \\
\hline $\mathrm{TC}(\mathrm{mmol} / \mathrm{L})$ & 0.101 & 0.076 & 0.126 & $<0.001$ \\
\hline $\mathrm{FBG}(\mathrm{mmol} / \mathrm{L})$ & 0.057 & 0.034 & 0.079 & $<0.001$ \\
\hline $\mathrm{UA}(\mu \mathrm{mol} / \mathrm{L})$ & 0.001 & 0.001 & 0.002 & $<0.001$ \\
\hline $\mathrm{CRP}(\mathrm{mg} / \mathrm{L})$ & -0.000 & -0.007 & 0.006 & 0.894 \\
\hline $\mathrm{Cr}(\mu \mathrm{mol} / \mathrm{L})$ & -0.001 & -0.002 & 0.001 & 0.353 \\
\hline
\end{tabular}

Adjusted for marital status, smoking status, work type, education level, physical exercise, and income. ${ }^{\mathrm{a}} \mathrm{BMI}<24$. ${ }^{\mathrm{b}} \mathrm{BMI} \geq 24$.

Table 4. Mediation effect on the development of NAFLD

\begin{tabular}{|c|c|c|c|c|c|}
\hline & Total effect & NDE & NIE & $p$ value & $\mathrm{PM}, \%$ \\
\hline \multicolumn{6}{|c|}{ Mediation effect of TG on the association between BMI and NAFLD } \\
\hline Low-BMI group ${ }^{a}$ & $1.421(1.326-1.523)$ & $1.365(1.246-1.497)$ & $1.041(0.989-1.096)$ & 0.127 & 13.269 \\
\hline High-BMI group ${ }^{b}$ & $1.135(1.030-1.250)$ & $1.100(0.993-1.219)$ & $1.032(1.007-1.057)$ & 0.010 & 26.050 \\
\hline
\end{tabular}

Adjusted for gender, age, systolic blood pressure, smoking status, marital status, work type, education level, physical exercise, income level, TC, FBG, UA, CRP, and Cr. NDE, natural direct effect; NIE, natural indirect effect; $\mathrm{PM}$, percent mediation. ${ }^{\mathrm{a}} \mathrm{BMI}<24 .{ }^{\mathrm{b}} \mathrm{BMI} \geq 24$.

\section{Discussion}

NAFLD is characterized by lipid accumulation in more than $5 \%$ of hepatocytes [1]. NAFLD affects $30 \%$ of the adult population in developed countries [16] and it has become the most common cause of HCC in both the USA and the UK $[17,18]$. The diagnosis of NAFLD in our study was determined by liver ultrasonography and medical history, which are widely used to diagnose NAFLD
[19], even though the gold standard is liver biopsy. NAFLD may predict a great deal of diseases such as cardiovascular diseases, type 2 diabetes, metabolic syndrome, retinal artery lesions, and even symptomatic cholelithiasis [20-23].

Obesity may raise serum TG levels as one of the acquired causes of hypertriglyceridemia, and it is often associated with an elevation in serum cholesterol. Several previous studies have reported that the association 
between obesity and hypertriglyceridemia may be mediated by IR $[24,25]$. In addition, IR is widely acknowledged as the main pathogenesis of NAFLD, and obesity and hypertriglyceridemia are closely related to IR, which leads to the development and progression of NAFLD. The factors mentioned above may indicate incompletely specified associations between BMI, TG, and NAFLD.

This large cohort study selected 2 potential risk factors (BMI and TG) for NAFLD and concluded that high BMI levels are associated with an increased risk of developing NAFLD in both low- and high-BMI groups, while BMI remained a risk factor for hypertriglyceridemia, consistent with previous studies. In addition, the mediation analysis showed that TG mediated approximately $26.050 \%$ of the association between BMI and NAFLD development in the high-BMI group (BMI $\geq 24$ ).

Hypertriglyceridemia and obesity are closely related to NAFLD. In the current study, high TG levels appeared to increase the risk of developing NAFLD in the high-BMI group, consistent with previous studies [26, 27].

$\mathrm{BMI}$ was proven to be an independent risk factor for NAFLD in our study, but it is difficult to prove that TG mediates the relationship between BMI and NAFLD development in clinical trials. However, on the basis of Tables 2 and 3, our mediation analysis revealed that TG contributed to $26.050 \%$ of the association in the high-BMI group, suggesting that high TG levels may contribute to the development of NAFLD in people with obesity. The results of the mediation analysis may be explained by IR. People with obesity may be more prone to developing IR than those with a low or normal weight, leading to the large effect of TG on the relationship between BMI and NAFLD development. Regarding the other $73.950 \%$ of the association, other unknown factors may play a more significant role in mediating the association between BMI and NAFLD.

NAFLD patients are at an increased risk for multisystem dysfunction (e.g., coronary, cerebrovascular, and peripheral vascular diseases) compared to those without NAFLD [28-31]. Patients with hypertriglyceridemia have a higher risk of developing NAFLD than those with a normal TG level. If a patient has a high TG level, and his/her BMI exceeds the normal upper range to the standard of overweight or obesity, then the patient is at a significantly increased risk of developing more serious liver diseases, such as cirrhosis or even HCC.

There were some limitations to this study. First, enrolling bias could not be eliminated because most of the participants in this study were incumbent or retired coal miners, which was reflected in the high number of participants engaged in physical work at baseline. Second, the diagnosis of NAFLD in our study was based merely on liver ultrasound; therefore, the diagnosis would not be accurate without liver biopsy as the gold standard for identifying steatosis.

Our study also had some strengths. First, this was a large cohort study. Second, this study could be used to determine the strength of TG in mediating the relationship between BMI and incident NAFLD and to provide an alternative method to predict the risk of liver condition. Finally, participants with a long history of taking medicines to lower serum TG levels and lose weight (i.e., drug-induced liver injury) were excluded from this study.

In conclusion, BMI is an independent risk factor for incident NAFLD while TG is associated with incident NAFLD in the high-BMI group (BMI $\geq 24$ ); TG contributes to only $26.050 \%$ of the relationship between BMI and NAFLD in people with obesity (BMI $\geq 24$ ). Other unknown factors may play a more significant role in mediating the association between BMI and NAFLD.

\section{Acknowledgement}

The authors thank all of the participants and their relatives and the members of the survey teams in the 11 regional hospitals of the Kailuan Group, as well as the project development and management team in the Kailuan Group.

\section{Statement of Ethics}

The current research was conducted ethically in accordance with the guidelines of the World Medical Association Declaration of Helsinki and all of the participants provided written informed consent. The study protocol was approved by the Ethics Committee of the Kailuan General Hospital (the ethical approval No. 20065) [11]. The study protocol and informed consent form are available; others are not available or applicable.

\section{Conflict of Interest Statement}

The authors have no conflict of interests to declare.

\section{Funding Sources}

This study was supported by grants from the Digestive Medical Coordinated Development Center of Beijing Hospitals Authority (No. XXZ01 and XXZ02), Promotion of Whole Chain Technology 
in Prevention, Diagnosis, and Treatment of Early Gastrointestinal Cancer in Beijing, Tianjin, and Hebei (No. Z171100004517009), and the National Natural Science Foundation of China (No. 81802310).

\section{Author Contributions}

J.X., X.G., Q.Z., and X.S. are responsible for the study conception and design. J.X., X.G., and Q.Z. drafted, revised, and edited this paper. S.W. and S.C. contributed with data collection. J.X., X.G., Q.Z., S.C., S.W., and X.S. read and approved the final version of this paper and agree with the order of the presentation of the authors.

\section{References}

1 European Association for the Study of the Liver (EASL) European Association for the Study of Diabetes (EASD) European Association for the Study of Obesity (EASO). EASLEASD-EASO Clinical Practice Guidelines for the management of non-alcoholic fatty liver disease. J Hepatol. 2016 Jun;64(6):1388-402.

2 Wong RJ, Aguilar M, Cheung R, Perumpail RB, Harrison SA, Younossi ZM, et al. Nonalcoholic steatohepatitis is the second leading etiology of liver disease among adults awaiting liver transplantation in the United States. Gastroenterology. 2015 Mar;148(3):547-55.

3 Hou XH, Zhu YX, Lu HJ, Chen HF, Li Q, Jiang $S$, et al. Non-alcoholic fatty liver disease's prevalence and impact on alanine aminotransferase associated with metabolic syndrome in the Chinese. J Gastroenterol Hepatol. 2011 Apr;26(4):722-30.

4 Masarone M, Federico A, Abenavoli L, Loguercio C, Persico M. Non alcoholic fatty liver: epidemiology and natural history. Rev Recent Clin Trials. 2014;9(3):126-33.

5 Hamaguchi M, Kojima T, Takeda N, Nakagawa T, Taniguchi H, Fujii K, et al. The metabolic syndrome as a predictor of nonalcoholic fatty liver disease. Ann Intern Med. 2005 Nov; 143(10):722-8.

6 Sanyal AJ, Campbell-Sargent C, Mirshahi F, Rizzo WB, Contos MJ, Sterling RK, et al. Nonalcoholic steatohepatitis: association of insulin resistance and mitochondrial abnormalities. Gastroenterology. 2001 Apr; 120(5): 1183-92.

7 Benedict M, Zhang X. Non-alcoholic fatty liver disease: an expanded review. World J Hepatol. 2017 Jun;9(16):715-32.

8 Townsend SA, Newsome PN. Non-alcoholic fatty liver disease in 2016. Br Med Bull. 2016 Sep;119(1):143-56.

9 Wu S, Huang Z, Yang X, Zhou Y, Wang A, Chen L, et al. Prevalence of ideal cardiovascular health and its relationship with the 4-year cardiovascular events in a northern Chinese industrial city. Circ Cardiovasc Qual Outcomes. 2012 Jul;5(4):487-93.

10 Hamaguchi M, Kojima T, Itoh Y, Harano Y, Fujii K, Nakajima T, et al. The severity of ultrasonographic findings in nonalcoholic fatty liver disease reflects the metabolic syndrome and visceral fat accumulation. Am J Gastroenterol. 2007 Dec;102(12):2708-15.
11 Wu S, Jin C, Li S, Zheng X, Zhang X, Cui L, et al. Aging, Arterial Stiffness, and Blood Pressure Association in Chinese Adults. Hypertension. 2019 Apr;73(4):893-9.

12 Chen S, Li W, Jin C, Vaidya A, Gao J, Yang H, et al. Resting Heart Rate Trajectory Pattern Predicts Arterial Stiffness in a CommunityBased Chinese Cohort. Arterioscler Thromb Vasc Biol. 2017 Feb;37(2):359-64.

13 Wang $\mathrm{M}$, Chu C, Mu J. Relationship between body mass index changes and blood pressure changes from childhood to adulthood in a general Chinese population: a 26 year cohort follow-up study. Blood Press. 2016 Oct;25(5): $319-26$.

14 Huang S, Li J, Shearer GC, Lichtenstein AH, Zheng X, Wu Y, et al. Longitudinal study of alcohol consumption and HDL concentrations: a community-based study. Am J Clin Nutr. 2017 Apr;105(4):905-12.

15 Li J, Huang Z, Hou J, Sawyer AM, Wu Z, Cai J, et al. Sleep and CKD in Chinese Adults: A Cross-Sectional Study. Clin J Am Soc Nephrol. 2017 Jun;12(6):885-92.

16 Chalasani N, Younossi Z, Lavine JE, Diehl AM, Brunt EM, Cusi K, et al.; American Association for the Study of Liver Diseases; American College of Gastroenterology; American Gastroenterological Association. The diagnosis and management of non-alcoholic fatty liver disease: Practice guideline by the American Association for the Study of Liver Diseases, American College of Gastroenterology, and the American Gastroenterological Association. Am J Gastroenterol. 2012 Jun;107(6):811-26.

17 Yu J, Shen J, Sun TT, Zhang X, Wong N. Obesity, insulin resistance, NASH and hepatocellular carcinoma. Semin Cancer Biol. 2013 Dec;23(6 6 Pt B):483-91.

18 Dyson J, Jaques B, Chattopadyhay D, Lochan R, Graham J, Das D, et al. Hepatocellular cancer: the impact of obesity, type 2 diabetes and a multidisciplinary team. J Hepatol. 2014 Jan; 60(1):110-7.

19 Sanyal AJ; American Gastroenterological Association. AGA technical review on nonalcoholic fatty liver disease. Gastroenterology. 2002 Nov;123(5):1705-25.

20 Yang W, Xu H, Yu X, Wang Y. Association between retinal artery lesions and nonalcoholic fatty liver disease. Hepatol Int. 2015 Apr; 9(2):278-82.
21 Khaw KB, Choi RH, Kam JH, Chakraborty B, Chow PK. Interval increase in the prevalence of symptomatic cholelithiasis-associated non-alcoholic fatty liver disease over a tenyear period in an Asian population. Singapore Med J. 2017 Dec;58(12):703-7.

22 Bedogni G, Miglioli L, Masutti F, Tiribelli C, Marchesini G, Bellentani S. Prevalence of and risk factors for nonalcoholic fatty liver disease: the Dionysos nutrition and liver study. Hepatology. 2005 Jul;42(1):44-52.

23 Knobler H, Schattner A, Zhornicki T, Malnick SD, Keter D, Sokolovskaya N, et al. Fatty liver-an additional and treatable feature of the insulin resistance syndrome. QJM. 1999; 92(2):73-9.

24 Badawi A, Klip A, Haddad P, Cole DE, Bailo BG, El-Sohemy A, et al. Type 2 diabetes mellitus and inflammation: prospects for biomarkers of risk and nutritional intervention. Diabetes Metab Syndr Obes. 2010 May;3: 173-86.

25 Bray GA, Clearfield MB, Fintel DJ, Nelinson DS. Overweight and obesity: the pathogenesis of cardiometabolic risk. Clin Cornerstone. 2009;9(4):30-40.

$26 \mathrm{Hu}$ Y, Liu J, Dong X, Xu Y, Leng S, Wang G. Clinical Study of Serum Homocysteine and Non-Alcoholic Fatty Liver Disease in Euglycemic Patients. Med Sci Monit. 2016 Nov;22: 4146-51.

27 Grander C, Grabherr F, Moschen AR, Tilg H. Non-Alcoholic Fatty Liver Disease: Cause or Effect of Metabolic Syndrome. Visc Med. 2016 Oct;32(5):329-34.

28 Choi SY, Kim D, Kim HJ, Kang JH, Chung SJ, Park MJ, et al. The relation between non-alcoholic fatty liver disease and the risk of coronary heart disease in Koreans. Am J Gastroenterol. 2009 Aug; 104(8):1953-60.

29 Treeprasertsuk S, Lopez-Jimenez F, Lindor KD. Nonalcoholic fatty liver disease and the coronary artery disease. Dig Dis Sci. 2011 Jan; 56(1):35-45.

30 Nseir W, Shalata A, Marmor A, Assy N. Mechanisms linking nonalcoholic fatty liver disease with coronary artery disease. Dig Dis Sci. 2011 Dec;56(12):3439-49.

31 Krawczyk M, Bonfrate L, Portincasa P. Nonalcoholic fatty liver disease. Best Pract Res Clin Gastroenterol. 2010 Oct;24(5):695-708. 